\title{
O CURRÍCULO EM MOVIMENTO: a Educação Física nos anos iniciais do Ensino Fundamental em Brasília
}

\author{
Juliana de Oliveira Freire \\ Universidade de Brasília - UnB \\ Ingrid Dittrich Wiggers \\ Universidade de Brasília - UnB \\ Aldecilene Cerqueira Barreto \\ Universidade de Brasília - UnB
}

\begin{abstract}
Resumo
O presente estudo tem por objetivo analisar a proposta para a Educação Física nos anos iniciais do Ensino Fundamental das escolas públicas de Brasília no Currículo de 2014. Caracteriza-se como pesquisa documental, com abordagem qualitativa. A interpretação dos dados realizou-se por meio da análise de conteúdo. Inferimos que o Currículo de 2014 apresenta fundamentos críticos e pós-críticos, mas os objetivos e conteúdos também expressam preceitos de teorias tradicionais. Na proposta pedagógica para a Educação Física nos anos iniciais do Ensino Fundamental - o Projeto Educação com Movimento -, destaca-se a indicação do trabalho em parceria entre professores de Educação Física e pedagogos, sem hierarquizações, mas a partir de uma relação de interdisciplinaridade e complementaridade. Concluiu-se que o Currículo de 2014 reflete disputas do campo acadêmicocientífico da Educação Física.
\end{abstract}

Palavras-chave: Currículo. Infância. Educação Física. Brasília.

\begin{abstract}
This study aims to analyze the purpose of Physical Education on Elementary School in Brasília public schools on the Curriculum of 2014. The methodology is characterized as documentary research, with a qualitative approach and the interpretation of the data was realized by content analysis. We can infer that the Curriculum of 2014 presents critical and post-critical foundations, but the objectives and subjects also express precepts of traditional theories. In the pedagogical proposal for Physical Education in the first years of Elementary School - Project Education with Movement - it is important to point out the work in partnership between Physical Education teachers and pedagogues, without hierarchizations, but based on a relation of interdisciplinarity and complementarity. We concluded that the Curriculum of 2014 reflects disputes from the academic-scientific field of Physical Education.
\end{abstract}

Keywords: Curriculum. Childhood. Physical Education. Brasília. 


\section{Introdução}

Neste trabalho, buscamos analisar a proposta para a Educação Física nos anos iniciais do Ensino Fundamental das escolas públicas de Brasília ${ }^{1}$ no Currículo de 2014, intitulado Currículo em Movimento. Para tanto, partimos da compreensão da organização curricular da educação em nível nacional, em cujos parâmetros se fundamenta o referido documento. A legislação brasileira é composta pela Lei de Diretrizes e Bases da Educação Nacional (LDB), Lei no 9.394/96 (Brasil, 1996), Diretrizes Curriculares Nacionais para a Educação Básica (Brasil, 2013) e Parâmetros Curriculares Nacionais (PCN) (Brasil, 1997). Esses documentos são materializados nos currículos, de responsabilidade das secretarias de educação no âmbito estadual, municipal e distrital. Nesse contexto, destacamos ainda os projetos políticospedagógicos (PPP) elaborados de acordo com a realidade de cada escola para subsidiar o planejamento pedagógico. É importante ressaltar a recente elaboração de uma Base Nacional Comum Curricular (Brasil, 2017), que ocorreu de modo controverso, com debates favoráveis e contrários à proposta.

Em Brasília, desde a promulgação da Constituição Federal de 1988, foram implementados pela Secretaria de Estado de Educação do Distrito Federal (SEDF), órgão responsável pela gestão da educação em Brasília, seis edições de currículos, publicados nos anos de 1993, 2000, 2009, 2011, 2014 e 2018. Atualmente, está em vigor a segunda edição do Currículo em Movimento (Distrito Federal, 2018). Todavia, o presente estudo tomou como objeto de análise a versão de 2014. Complementarmente, examinamos o Projeto Educação com Movimento: Educação Física na Educação Infantil e nos anos iniciais do Ensino Fundamental - PECM ${ }^{2}$ (Distrito Federal, 2016), orientação pedagógica que detalha a inserção dos professores de Educação Física nesses níveis de ensino.

Pesquisas nacionais apontam a necessidade de estudos sobre o tema currículo no campo da Educação Física. Betti, Ferraz e Dantas (2011), ao analisar o estado da arte da Educação Física escolar a partir das produções brasileiras, indicam a insuficiência de pesquisas sobre o currículo. Os autores entendem que diversas produções que criticam as propostas curriculares, por vezes, não ultrapassam o julgamento ideológico ou o caráter de denúncia. Assim, reiteram a premência de se problematizarem as análises dos currículos de modo mais amplo e profundo. Ao investigar as tendências das pesquisas em Educação Física na Europa, Kirk (2010) destaca a relevância de se ampliarem as investigações que tratem da categoria temática currículo/conhecimento.

A partir dessas iniciativas, entendemos que a definição do objeto da presente pesquisa é pertinente, visto que pode contribuir para o debate acerca das relações entre o currículo e a prática pedagógica da Educação Física escolar com crianças, aprofundando a discussão sobre o tema.

Essas considerações teóricas, ao mesmo tempo em que se configuram incitantes da pesquisa, são evidenciadas direta ou indiretamente em outros trabalhos. Dentre as pesquisas sobre currículos da SEDF, destaca-se a de Oliveira (2014), que comparou as Artes Visuais nos currículos de 2000, 2009 e 2011. Gramorelli (2014) realizou pesquisa em que analisou as apropriações do termo cultura-corporal no Currículo de 2014, em comparação com documentos de outros estados brasileiros. Esses trabalhos, entretanto, não trataram especificamente da Educação Física dos anos iniciais do Ensino Fundamental, enfoque por nós privilegiado. A seguir, apresentamos o referencial teórico que subsidia a discussão por nós empreendida.

\section{Currículo}

A origem histórica da palavra currículo deriva do latim curriculum, com a mesma raiz de cursus e currere. De acordo com Sacristán (2013), na Roma Antiga, cursus honorum 
representava as honras que o cidadão acumulava ao ocupar cargos eletivos e judiciais. No nosso idioma, permanece com a conotação de percurso da vida profissional (curriculum vitae) e, no contexto educacional, representa a organização dos conteúdos e a sequência em que devem ser ensinados e aprendidos. Nessa direção, Sacristán (2013, p. 17) afirma que:

O conceito de currículo e a utilização que fazemos dele aparecem desde os primórdios relacionados à ideia de seleção de conteúdos e de ordem na classificação dos conhecimentos que representam, que será a seleção daquilo que será coberto pela ação de ensinar.

A palavra currículo tem duas denotações: uma refere-se ao "conhecimento tratado pedagógica e didaticamente pela escola e que deve ser aprendido e aplicado pelo aluno", enquanto a outra trata do "conjunto de experiências a serem vividas pelo estudante sob a orientação da escola” (Moreira, 2010, p. 12).

Apple (2008) compreende a educação como um instrumento de manutenção de poder, considerando aspectos macroestruturais da sociedade. Nessa perspectiva, o autor faz uma análise crítica da educação escolar como dispositivo de preservação do poder econômico, político e cultural que ultrapassa questões técnicas de ensinar com eficiência e eficácia. $\mathrm{O}$ pesquisador defende que a ideologia implícita na elaboração dos currículos está relacionada aos gestores, os quais, por vezes, não detêm conhecimento da realidade ou da prática pedagógica cotidiana. Assim, segundo o autor, na análise do currículo, faz-se necessário pensar também nos condicionantes sociais que os influenciam na prática, pois o neoliberalismo e o neoconservadorismo econômico interferem na sociedade e, consequentemente, na educação.

Ainda a esse respeito, Adamson e Morris (2007) definem seis ideologias que inspiram a elaboração dos currículos: racionalismo acadêmico (foco no conteúdo); eficiência social e econômica (conhecimentos aplicáveis em um futuro emprego); reconstrutivismo social (melhoria da sociedade por meio da educação); ortodoxia (ensino de ideologia política ou religiosa); progressivismo (desenvolvimento do indivíduo) e pluralismo cognitivo (múltiplas aprendizagens).

De acordo com Silva (2002), os estudos curriculares tiveram destaque a partir da década de 1920, nos Estados Unidos, com John Bobbit e seus pressupostos de eficiência da educação e burocratização do currículo. Com o movimento conhecido como reconceptualização curricular e a Nova Sociologia, nos Estados Unidos e na Inglaterra, respectivamente, houve um rompimento do paradigma da eficiência e da racionalidade técnica em meados da década de 1970 .

Com base nessa compreensão, Silva (2002) estrutura as diferentes teorias de currículo em três grupos: tradicionais, críticas e pós-críticas. O autor argumenta que a visão de ser humano e de sociedade, bem como a identidade ou a subjetividade, influencia a elaboração do currículo e a compilação do que se julga importante ou do que se considera ideal. As teorias tradicionais se caracterizam por neutralidade, cientificidade e questões técnicas e organizacionais. Em contrapartida, as críticas centram-se nas questões predominantemente sociais, econômicas e ideológicas que perpassam os currículos, enquanto as pós-críticas, além desses aspectos, acrescentam questões de gênero, raça, etnia e multiculturalismo.

Nos currículos, é possível perceber os princípios daqueles que os elaboraram. Bourdieu (2004) faz uma distinção entre agentes detentores de poder temporal e poder específico. O poder temporal refere-se à ocupação temporária de cargos ou posições importantes. Por sua vez, o poder específico ou de prestígio é representado pelo reconhecimento de profissionais que contribuam com o campo por seu saber. Seguindo essa lógica, a exclusão ou a inclusão depende da perspectiva dos gestores, ou seja, sujeitos investidos de poder para concretizar tal intento. Em determinados momentos, esses agentes com poder temporal lançam mão de convidar especialistas, que detêm o poder específico para subsidiar ou mesmo elaborar os documentos. 
Nesse entendimento, são tecidas críticas aos currículos que são discutidos entre especialistas e gestores, pois não propiciam espaço para a participação dos atores em diversos níveis. Em consequência, "o currículo é sempre o resultado de uma seleção: de um universo mais amplo de conhecimentos e saberes seleciona-se aquela parte que vai constituir, precisamente, o currículo" (Silva, 2002, p. 15).

Nesse âmbito, destaca-se a homologação, pelo Ministro da Educação, da versão final ${ }^{3}$ da Base Nacional Comum Curricular - BNCC (Brasil, 2017). Trata-se de um conjunto de orientações que estabelece conteúdos e sequência que, obrigatoriamente, deverão ser respeitados em todos os níveis da educação básica brasileira. "A Base estabelece conhecimentos, competências e habilidades que se espera que todos os estudantes desenvolvam ao longo da escolaridade básica” (Brasil, 2017). Ainda segundo informações do Ministério da Educação, a BNCC contribuirá para aumentar a qualidade do ensino, reduzirá as disparidades entre o ensino em diferentes locais, como as zonas rurais e urbanas, ou entre periferias e grandes cidades e entre escolas particulares e públicas, além de promover a colaboração entre as três esferas do governo, buscando superar a fragmentação das políticas educacionais.

Todavia, diversos pesquisadores do currículo apresentam críticas à BNCC. Para Cunha (2015, p. 585), a base “[...] resultará de antagonismos e exclusões, não terá pouso final, não recobrará a uma origem ou à verdade toda vez que for pronunciado [...]”. Portanto, a elaboração de uma base nacional para o currículo, por si só, não resolverá os problemas da educação, não garantirá a identidade da escola, tampouco aprimorará a Educação Básica.

\section{Currículo e infância}

Buscando uma aproximação entre o currículo e a infância, é notório que, no sistema educacional brasileiro, os tempos e espaços escolares são tradicionalmente pensados por adultos, cuja tendência é homogeneizar as crianças a partir de critérios de idade e conteúdo que as reúnem em uma única etapa, série, ano ou ciclo. Estudos sobre infância em distintos campos disciplinares, sobretudo no século XX, indicam que os adultos percebem as crianças como seres que não são, mas estão em preparação para virem a ser. A etimologia da palavra infante, que significa “o sem fala”, repercute no modo etapista e evolucionista de conceber a infância como primitiva e inacabada.

Um dos autores precursores no trato da temática infância e currículo foi o americano John Dewey, que criticou essa visão. Em seu livro The child and the curriculum, impresso pela primeira vez em 1899, o autor afirma a necessidade de correlação entre teoria e prática no campo pedagógico. Com base no pragmatismo, concepção filosófica que elaborou uma crítica à filosofia tradicional, o autor busca distanciar-se de um currículo tradicional e teórico, pois, para Dewey (1963), preparar as crianças para a vida significa dar-lhes oportunidade de se descobrirem e desenvolverem suas capacidades a partir da experiência.

Tal assertiva reforça a necessidade de aliar teorias renovadoras às formulações dos currículos, à formação dos professores e à prática pedagógica, com vistas a superar esses entraves a um desenvolvimento de sujeitos críticos e detentores de direitos. Sendo assim, as múltiplas formas de expressão e linguagem da criança, como a leitura, a imaginação, a ludicidade, o corpo, a dança, a arte e o desenho, representam possibilidades heurísticas para a organização do trabalho pedagógico de um professor que vislumbre o protagonismo das crianças (Gobbi; Pinazza, 2014).

Por conseguinte, o conceito de infância exerce influência sobre a elaboração dos currículos e, consequentemente, sobre a prática pedagógica. Arroyo (2013) destaca que a pedagogia e o sistema educacional, a própria docência e sua formação, os currículos e seus saberes não consideram as especificidades e necessidades da infância. Por isso as crianças, na escola, muitas 
vezes, são tratadas como escolares, e não como crianças, o que constitui desrespeito ao tempo em que vivem. Um exemplo foi a ampliação do Ensino Fundamental de oito para nove anos (Brasil, 2006). As crianças de seis anos passaram de pré-escolares a escolares, medida que limitou o pouco direito que já tinham e levou-as a "prematuramente perder a condição de crianças, perder seu pertencimento ao tempo da infância, como as crianças maiores de 7 a 10 anos já perderam” (Arroyo, 2013, p. 186). O autor critica ainda a característica etapista, cognitivista e regularizadora do currículo.

Por outro lado, o currículo não é apenas um campo de disputas teóricas, mas um espaço para os sujeitos da ação educativa se posicionarem ativamente na luta por seus direitos. Arroyo (2013) considera os movimentos de grupos minoritários - negros, quilombolas e indígenas um avanço em busca de exercer influências para que os resultados das suas lutas também sejam refletidos nos documentos curriculares.

No esteio dessas discussões, inserem-se os estudos sobre infância, pois, segundo Corsaro (2011), a ampliação das reivindicações de grupos minoritários alargou o espaço para os estudos da infância. Por intermédio de suas investigações com crianças, o autor evidenciou um modo peculiar de interação, o qual denominou cultura de pares, em que a criança não internaliza os conhecimentos e as habilidades linearmente, mas ressignifica esse aprendizado de acordo com suas experiências e percepções. Essas formulações partem de uma perspectiva de criança enquanto sujeito social, cultural e histórico, possuidora de direitos, e não apenas receptora passiva de processos de ensino-aprendizagem. A alteridade na infância se apresenta como uma possibilidade para superar a hierarquia reducionista referenciada no mundo adulto (Gouvêa, 2011).

\section{Currículo, infância e educação física}

No campo da Educação Física, Ferraz e Correia (2012) analisaram o desenvolvimento das teorias curriculares relacionadas às concepções teóricas desse componente e suas repercussões nos debates da formação docente. Os autores consideram a relevância de uma aproximação entre discussões teóricas e acadêmicas e professores que atuam na prática, para que o currículo seja construído de modo inovador e crítico, refletindo as demandas da Educação Física Escolar na atualidade.

A partir de uma revisão sistemática em periódicos de 1990 a 2013, do campo da educação e da Educação Física, Rocha et al. (2015) discutiram como as teorias de currículo têm influenciado a Educação Física escolar. Os pesquisadores concluíram que os currículos têm se distanciado das teorias tradicionais e intentam superar a centralidade em aspectos puramente técnicos, incorporando elementos das teorias críticas em $74 \%$ dos artigos. Cabe ressaltar a influência paulatina das teorias pós-críticas nos trabalhos analisados.

Outro fator relevante relacionado ao currículo e à Educação Física diz respeito à prática pedagógica, a qual não depende exclusivamente das orientações dos documentos, mas perpassa a qualidade da formação inicial que incidirá na capacidade crítica do professor no que toca ao planejamento e à realidade de suas aulas. Sobre esta questão, Lacerda e Costa (2012) analisaram se o currículo da formação inicial de uma universidade estadual baiana oferece subsídios para a atuação dos futuros professores que lecionarão na Educação Infantil. Apesar da ênfase da formação ser a escola em uma perspectiva crítica e emancipadora, com debates que permeiam relevantes questões da história da educação e da educação física, as autoras concluíram que há poucas referências a respeito desse nível de ensino. Além disso, as disciplinas que permeiam esse debate não apresentam as especificidades de que a atuação nesse segmento necessita. Portanto, é necessário possibilitar ao professor compreender "as contradições, peculiaridades e possibilidades pertinentes à primeira etapa da Educação Básica” (Lacerda; Costa, 2012, p. 339). 
Essas discussões são relevantes para que não se reforce a dicotomia entre teoria e prática, mas, sim, se produza uma reinterpretação da teoria com base na experiência em sala de aula, ou seja, o que não está explícito nos currículos oficiais nem no planejamento dos professores (Sanchotene; Molina Neto, 2006). Ao analisar os currículos da SEDF entre 2000 e 2011, Oliveira (2014, p. 47) destaca a existência de "diversos currículos, o institucional, o oculto, o selecionado pelas educadoras, o compreendido pelos educandos que também fazem, de certa forma, uma seleção do que aprender”. Diante do exposto, reitera-se a necessidade de uma formação inicial e continuada com qualidade, para que o professor tenha condições de estabelecer de forma consistente essas relações entre a teoria e a prática.

Nesse entremeio, se inserem os desafios do professor de Educação física em sua atuação com crianças, fase que difere de outros níveis de ensino por suas características e necessidades próprias. Lacerda e Costa (2012) alertam que a falta de entendimento das especificidades desse nível de ensino pode direcionar as aulas exclusivamente ao desenvolvimento das habilidades motoras ou utilizar as atividades corporais como mero apoio à aprendizagem de conteúdos de outras áreas de conhecimento, desfigurando a educação física de seu objeto, em vez de estabelecer uma desejada relação de interdisciplinaridade. Pode, ainda, destinar todo o tempo apenas à diversão ou à recreação para que as crianças extravasem ao máximo as energias e, no momento da "aula”, estejam quietas e comportadas para aprender o que é de fato "importante".

Ao tratar das concepções de infância na Educação física brasileira, Oliveira (2005) apresenta duas visões antagônicas: uma idealista, que considera o corpo uma estrutura fragmentada, biológica e cognitiva; e outra crítica, em que a criança é vista como um sujeito inserido em uma dada sociedade. Nessa concepção, o papel da Educação física é abordar o conhecimento em sua totalidade, buscando superar uma visão compensatória.

Buss-Simão et al. (2010), por outro lado, criticam essa dicotomia entre o biológico e o cultural, contrapondo os extremos e visualizando a possibilidade de um trabalho que não desconsidere ambos os aspectos. Conforme os autores, "infância e corpo devem ser compreendidos, simultaneamente, como construção cultural e biológica [...]” (Buss-Simão et al., 2010, p. 165). Concebem, desse modo, o ser humano como biocultural. Ayoub (2001) ressalta, ainda, o cuidado necessário para que a linguagem corporal não seja exclusivamente abordada nas aulas de Educação física.

Em pesquisa realizada com o intento de identificar as concepções de corpo, criança e educação na produção acadêmica a respeito dos estudos da infância, em 18 dissertações produzidas entre 1997 e 2003, Buss-Simão (2007) concluiu que a categoria geral "infância e criança” foi predominantemente considerada como sujeito histórico social e singular, e a educação integral, centrada nas múltiplas linguagens da criança, como arte, música, dança, movimento e brincadeiras. Esse levantamento aponta tendência emergente no sentido de superar a percepção fragmentária da criança. No âmbito das fontes pesquisadas, o corpo foi compreendido como construção social, cultural e histórica, conquanto criticada sua instrumentalização nas instituições educativas.

Sobre a percepção de conceitos em documentos elaborados por órgãos centrais dos sistemas de ensino brasileiros e suas influências na prática pedagógica, destacamos Moreira (2012), que analisou, por meio das narrativas dos professores de educação física que atuam na rede pública de ensino de Vitória, Espírito Santo, como eles se apropriaram das concepções de criança, infância, Educação Infantil e educação física. A autora concluiu que os professores se utilizam, de modo consciente ou não, de preceitos importantes a respeito da criança em seu contexto social como ponto de partida para a atuação na Educação Infantil. Todavia, considerou inexpressiva a contribuição específica desses documentos para a educação física. Com base no exposto, detalhamos a seguir a trajetória em busca do objetivo da pesquisa. 


\section{Caminho percorrido}

Para alcançar o objetivo de analisar a proposta para a educação física nos anos iniciais do Ensino Fundamental das escolas públicas de Brasília no Currículo de 2014, fizemos uma pesquisa documental, com abordagem qualitativa. A interpretação dos dados atendeu aos preceitos da análise de conteúdo, sintetizada por Bardin (2009). Segundo a autora, tal metodologia se organiza em três fases: pré-análise, exploração do material e tratamento dos resultados, inferência e observação.

A pré-análise consistiu na definição das questões de pesquisa, dos objetivos e dos documentos a serem analisados. Essa fase abarcou ainda uma revisão bibliográfica dos conceitos de currículo, educação física e infância, a fim de situar pesquisas realizadas anteriormente sobre a temática, conforme já evidenciado.

A fase de exploração do material e tratamento dos resultados envolveu a leitura e a análise do Currículo de 2014, enfocando o volume referente aos pressupostos teóricos, bem como o relacionado aos anos iniciais do Ensino Fundamental (Distrito Federal, 2014a; 2014b). Como fazem parte de um todo, apenas compõem volumes diferentes, ambos foram denominados ao longo do texto Currículo de 2014. Além desses documentos, foi analisado, em caráter complementar, o PECM (Distrito Federal, 2016), projeto que descreve aspectos técnicos e pedagógicos para tornar viável a atuação do professor de educação física na Educação Infantil e nos anos iniciais do Ensino Fundamental nas escolas públicas de Brasília.

A fim de apresentar os resultados, segue um breve panorama do contexto de elaboração dos documentos analisados e os critérios utilizados para apresentação, análise e discussão dos dados.

\section{Análise e discussão}

As discussões para a construção do Currículo de 2014 iniciaram em 2011 com a avaliação diagnóstica da versão experimental do currículo, elaborada em 2010. Para tanto, ocorreram plenárias em sete Coordenações Regionais de Ensino ${ }^{3}$ com a participação dos diferentes segmentos dos profissionais da educação. Cada plenária reuniu profissionais de duas Regionais de Ensino (Distrito Federal, 2014a).

Em 2012, os debates continuaram em grupos de trabalho, que sistematizaram as propostas das plenárias e elaboraram uma minuta denominada Currículo em Movimento, submetida às escolas. Essa análise ocorreu por meio do curso de formação continuada ${ }^{4}$ intitulado Currículo em Movimento: reorganização do trabalho pedagógico nos ciclos e na semestralidade, realizado nas escolas da rede pública de ensino. Ainda em 2013, o texto foi finalizado, e o processo culminou com sua distribuição a todas as escolas em 2014 (Distrito Federal, 2014a).

O Currículo de 2014 foi organizado em oito volumes, por níveis e modalidades de ensino. Na Figura 1, estão dispostos, na sequência da esquerda para a direita, os volumes:

1 - Pressupostos teóricos;

2 - Educação Infantil;

3 - Ensino Fundamental: anos iniciais;

4 - Ensino Fundamental: anos finais;
5 - Ensino Médio;

6 - Educação Profissional e a Distância;

7 - Educação de Jovens e Adultos;

8 - Educação Especial.

Em cada volume, há uma apresentação geral a respeito do currículo, seguida de elucidação sobre os diversos componentes curriculares. Para fins deste estudo, apenas os volumes 1 e 3 foram considerados como foco das análises (Distrito Federal, 2014a, 2014b). 
Figura 1: Currículo de 2014 - Currículo em Movimento da Educação Básica
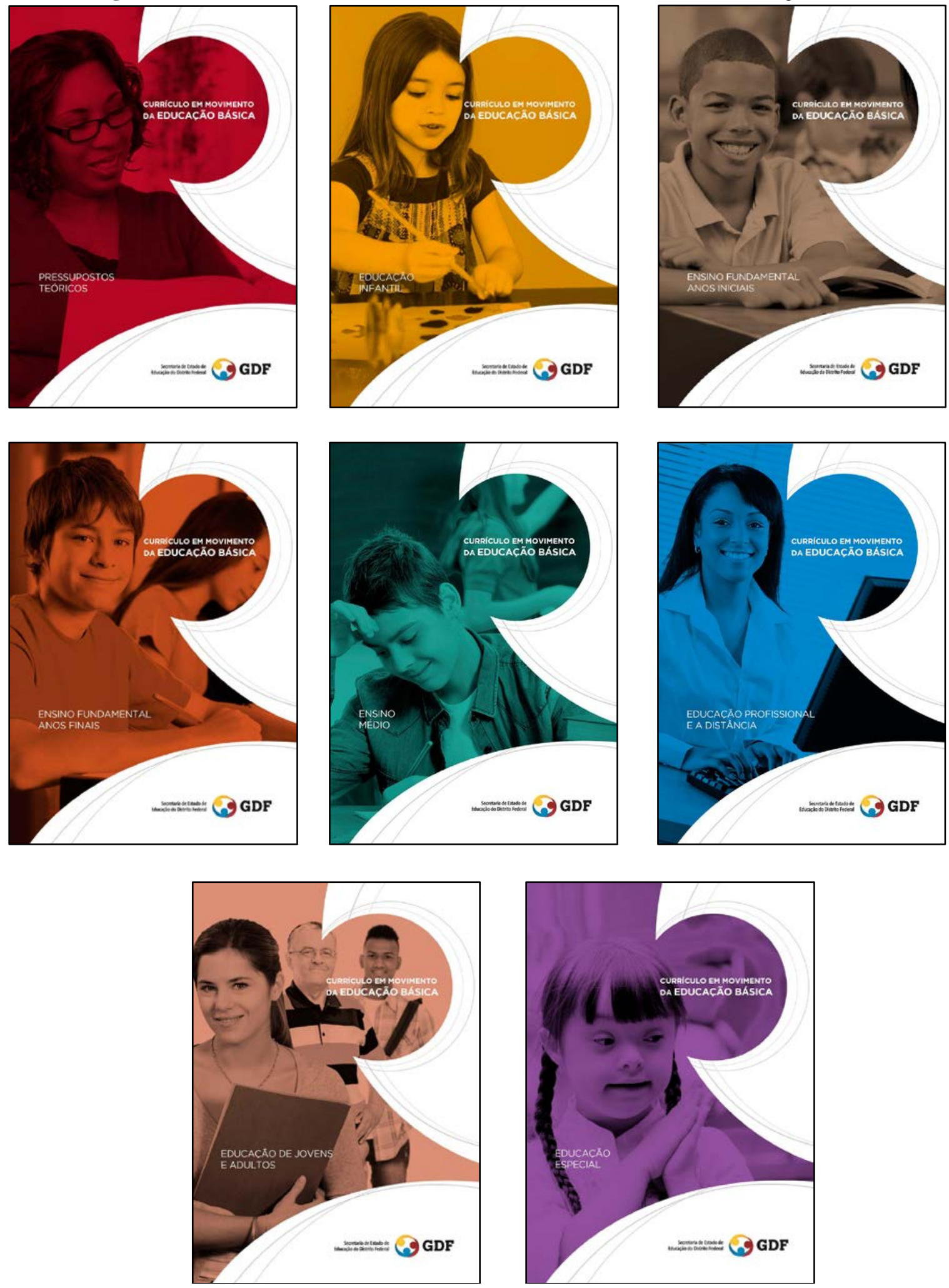

Fonte: Distrito Federal (2019)

O volume 3 - Ensino Fundamental: anos iniciais - apresenta elementos teóricos, detalhando objetivos e conteúdos para a educação física e para os demais componentes curriculares. Ressalve-se que, mesmo estando explícito na LDB (Brasil, 1996) que em todos os níveis de ensino a educação física é obrigatória, a presença de professor com formação 
específica na área é facultativa, conforme o art. 31 da Resolução $n^{\circ} 7$ do Conselho Nacional de Educação (Brasil, 2010).

Nas escolas públicas de Brasília, a atuação do professor de educação física na Educação Infantil e nos anos iniciais do Ensino Fundamental é garantida apenas naquelas escolas atendidas por projetos específicos, como o PECM. O principal objetivo desse projeto é ampliar as experiências corporais das crianças por meio de uma prática pedagógica interdisciplinar e integrada entre o professor de atividades e o de educação física (Distrito Federal, 2016). O PECM operacionaliza a atuação do professor de educação física, pois organiza pedagogicamente sua prática, articulando-se entre o currículo e o projeto político-pedagógico da escola. Seu texto é estruturado em: apresentação, objetivos, inserção da educação física na Educação Infantil e nos anos iniciais do Ensino Fundamental, fundamentos do currículo que norteiam o trabalho pedagógico do professor de educação física, base curricular orientadora para a educação infantil e para os anos iniciais do Ensino Fundamental, organização do trabalho pedagógico do professor, princípios de atendimento, metodologia e critérios de expansão e avaliação.

Além disso, o PECM é uma orientação pedagógica que está em vias de se tornar uma política de inserção do professor de educação física na Educação Infantil e nos anos iniciais do Ensino Fundamental, com o intuito de universalizar a educação física nas 439 unidades escolares que atendem a Educação Infantil e os anos iniciais do Ensino Fundamental. Enquanto o projeto for uma política de governo, poderá ser extinta a qualquer tempo, conforme deliberação dos gestores. Para torná-lo uma política de Estado, estão sendo realizadas ações como: inserção de metas no Plano Distrital de Educação de 2015 a 2024, instruído pela Lei no 5.499/2015 (Distrito Federal, 2015a), e no Plano Plurianual do Distrito Federal de 2016-2019 (Distrito Federal, 2015b), visando à ampliação gradual do número de escolas atendidas até a sua universalização em 2024.

Após evidenciar e discutir o contexto atual da educação física nos anos iniciais nas escolas públicas de Brasília, foram definidas cinco categorias de análise do Currículo de 2014: pressupostos teóricos, abordagem pedagógica da educação física, objetivos e conteúdos, infância no currículo, ciclos de aprendizagem.

\section{a) Pressupostos teóricos}

O Currículo de 2014, em seus objetivos para a educação, baseia-se em três pilares, quais sejam, as Diretrizes Curriculares Nacionais da Educação Básica (Brasil, 2013), a pedagogia histórico-crítica (Saviani, 2011) e a psicologia histórico-cultural (Vigotski, 1994). O trecho a seguir evidencia essa interpretação.

O Currículo da Educação Básica da Secretaria de Estado de Educação do Distrito Federal fundamenta-se na Pedagogia Histórico-Crítica e na Psicologia HistóricoCultural, opção teórico-metodológica que se assenta em inúmeros fatores, sendo a realidade socioeconômica da população do Distrito Federal um deles. Isso porque o Currículo escolar não pode desconsiderar o contexto social, econômico e cultural dos estudantes (Distrito Federal, 2014a, p. 30, grifo do autor).

Além disso, o documento reitera a importância do aspecto social no processo de desenvolvimento humano. É notadamente baseado nas teorias críticas e pós-críticas, como explicitado em seus pressupostos teóricos.

Ao considerar a relevância da opção teórica, a SEEDF elaborou seu Currículo a partir de alguns pressupostos da Teoria Crítica ao questionar o que pode parecer natural na sociedade, como: desigualdades sociais, hegemonia do conhecimento científico 
em relação a outras formas de conhecimento, neutralidade do currículo e dos conhecimentos, busca de uma racionalidade emancipatória para fugir da racionalidade instrumental, procura de um compromisso ético que liga valores universais a processos de transformação social (Distrito Federal, 2014a, p. 21, grifo nosso).

Segundo as teorias críticas e pós-críticas, não existe neutralidade na ciência, mas relações de poder em que se sobressaem os interesses dos mais abastados. Portanto, o currículo pode ser um espaço em que os interesses dos menos favorecidos sejam contemplados, propiciando a emancipação humana. Assim:

Para promover as conexões entre currículo e multiculturalismo, sem desconsiderar as relações de poder que estão na base da produção das diferenças, alguns pressupostos da Teoria Pós-Crítica também fundamentam este Documento (Distrito Federal, 2014a, p. 22, grifo nosso).

Seguindo esse pensamento, o currículo apresenta, além de elementos de teorias críticas, outros que se referem às teorias pós-críticas, as quais buscam superar as desigualdades sociais, pois estão pautadas no multiculturalismo e na inclusão. Por isso são propostos eixos transversais aos conteúdos: educação para a diversidade, cidadania, sustentabilidade e direitos humanos. Afirma o documento:

Os eixos transversais possibilitam o acesso do (a) estudante aos diferentes referenciais de leitura do mundo, com vivências diversificadas e a construção/reconstrução de saberes específicos de cada ciclo/etapa/ modalidade da educação básica. Os conteúdos passam a ser organizados em torno de uma determinada ideia ou eixo que indicam referenciais para o trabalho pedagógico a ser desenvolvido por professores (as) e estudantes, de forma interdisciplinar, integrada e contextualizada (Distrito Federal, 2014a, p. 37).

O objetivo das teorias pós-críticas é, além de perceber as diferenças, buscar a compreensão da gênese de sua existência, bem como as relações de poder implícitas nas questões oriundas da multiculturalidade, como etnia, gênero, raça ou religião. Com essa compreensão, os eixos transversais são materializados na elaboração do projeto político- pedagógico e em projetos desenvolvidos nas escolas.

Nessa direção, Ferraz e Correia (2012) consideram a aproximação entre as discussões teóricas e acadêmicas relevante para professores que atuam na prática. Assim, essa compreensão pode possibilitar a construção de um currículo inovador e crítico, que contemple a reflexão sobre as demandas da educação física escolar na atualidade. Entendemos, por conseguinte, que o Currículo de 2014 reflete a influência das teorias críticas e pós-críticas em seus fundamentos.

\section{b) Abordagem pedagógica da educação física}

Ao analisar a educação física no volume dos anos iniciais do Ensino Fundamental, ficou evidente que esta se insere no conjunto das linguagens, sendo compreendida como:

[...] importante manifestação da cultura corporal de movimento, que contribui para a formação global da criança por meio de brinquedo, de jogo simbólico, de movimentos gerais vivenciados mediante atividades orientadas, de iniciação das danças, de ginásticas e de jogos pré-desportivos, entre outras atividades que, ao oportunizar as aprendizagens, favoreçam o desenvolvimento geral do estudante. A Educação Física nos Anos Iniciais do Ensino Fundamental não pode ser tratada como 
uma mera atividade física que busque apenas o aperfeiçoamento motor ou que seja utilizada aleatoriamente, como ocupação do tempo ocioso da criança; tampouco ser usada como simples atividade de lazer, apartada do fazer pedagógico da escola (Distrito Federal, 2014b, p. 20).

A partir desse excerto, depreendemos que a abordagem que fundamenta a educação física no documento é a crítico-superadora, devido à utilização da nomenclatura cultura corporal ${ }^{5}$. Semelhantemente, analisando os documentos oficiais para a Educação Infantil prescritos pelos órgãos centrais de gestão dos sistemas de ensino, Moreira (2012) identificou que, apesar de orientarem o trabalho da linguagem corporal na perspectiva da cultura corporal, não mencionam a obra de referência: Coletivo de Autores (1992) ${ }^{6}$. Entretanto, Gramorelli (2014) ressalta que a utilização dessa terminologia na constituição das propostas curriculares oficiais nem sempre está se referindo à formação de um sujeito que compreende as práticas corporais construídas e acumuladas por diferentes processos vivenciados e criados pelo ser humano em determinada cultura, mas em algumas situações aponta apenas a ampliação dos conteúdos da educação física, incluindo jogos, esportes, lutas, ginásticas e danças.

Essa assertiva corrobora a LDB (Brasil, 1996), que legisla sobre a inserção da educação física como componente curricular e se fundamenta nos PCN (Brasil, 1997) ao tratar dos conteúdos com base nas manifestações da cultura corporal:

Lutas, danças, jogos, ginásticas e esportes fazem parte do imaginário de nossas crianças desde antes de entrarem para a escola. Dessa forma, devem ser introduzidos de forma essencialmente lúdica para que lhes sejam possível a vivência em múltiplas expressões do movimento humano. O enfoque dessa abordagem é mais abrangente à medida que valoriza e considera aspectos sócio-históricos de cada atividade trabalhada, como também o contexto em que os estudantes estão inseridos e as aprendizagens motoras individuais, independentemente do nível de habilidades que apresentem (Distrito Federal, 2014b, p. 21).

Sobre os aspectos sócio-históricos, inferimos a influência da perspectiva histórico-cultural de Vigotski (1994) na educação física, em consonância com o que está explicitado nos pressupostos teóricos do currículo (Distrito Federal, 2014a). Em pesquisa bibliográfica, Sampaio (2013) investigou as apropriações da teoria histórico-cultural por parte das abordagens da educação física nas décadas de 1980 e 1990. Identificou a apropriação por parte das abordagens construtivista-interacionistas e crítico-superadora. Além disso, destacou a importância do jogo e da brincadeira para a criança e como esses momentos reproduzem as contradições do seu contexto sócio-histórico.

\section{c) Objetivos e conteúdos da educação física}

No volume dos anos iniciais do Ensino Fundamental do Currículo de 2014, são apresentados quadros com conteúdos e objetivos de Linguagem, Matemática, História, Geografia, Ciências da Natureza e Ensino Religioso. São 79 objetivos e 96 conteúdos da educação física em um mesmo quadro organizado por ano $\left(1^{\circ}\right.$ ao $5^{\circ}$ ano), sem se estabelecerem relações diretas entre si. Alguns objetivos e conteúdos se repetem em diferentes anos, por isso, considerando apenas uma ocorrência, são 34 objetivos e 42 conteúdos ao todo.

Na proposta ora apresentada, enumeramos diversos objetivos visando atingir domínios motores, cognitivos e afetivo-sociais, sendo que muitos deles se repetem de um ano para outro, porém, com aprofundamento progressivo de acordo com o processo de aprendizagem do estudante em cada uma dessas dimensões (Distrito Federal, 2014b, p. 20). 
Na apresentação dos objetivos e conteúdos do Currículo de 2014, observamos uma pluralidade de abordagens da educação física. O uso de termos como habilidades primordiais, básicas, específicas e locomotoras se vincula claramente à abordagem desenvolvimentista (Tani, 1988). O objetivo de desenvolver elementos psicomotores indica a influência da psicomotricidade (Le Boulch, 2007). Ao tratar de cooperação, interação e convivência harmônica com os demais colegas, respeito às regras e jogos cognitivos, inferimos elementos da abordagem construtivista-interacionista (Freire, 1997).

Segundo Bracht (1999), as abordagens supracitadas se vinculam às matrizes acríticas da educação ao não considerarem a função social da educação física. Nessa direção, Rocha et al. (2015) ensinam que tais abordagens se aproximam das teorias tradicionais de currículo por coincidirem com o ideal essencialmente prescritivo das práticas corporais.

Por outro lado, objetivos e conteúdos que tratam explicitamente das manifestações de elementos da cultura corporal sugerem a presença da abordagem crítico-superadora (Coletivo de Autores, 1992). Por fim, a compreensão crítica do esporte no contexto da mídia e da escola nos direciona à abordagem crítico-emancipatória (Kunz, 1994).

Importante destacar que as abordagens crítico-superadora e crítico-emancipatória, como os nomes sugerem, fundamentam-se em pressupostos condizentes com as teorias críticas de currículo. A abordagem crítico-superadora considera sobremaneira a influência dos condicionantes sociais à educação, sendo a cultura corporal construída historicamente pelo ser humano o objeto da educação física, com vistas à suplantação do sistema capitalista. Nessa abordagem, o professor tem a responsabilidade de auxiliar a criança a superar sua condição alienada e passiva diante das influências da cultura dominante. Andrade Filho (2011) discute a limitação dessa abordagem no âmbito da educação física na Educação Infantil, por manter o foco no professor, em uma relação de subserviência e falta de autonomia, reforçando a visão de incompletude da criança.

Por sua vez, a abordagem crítico-emancipatória estruturou uma proposta para a educação física de crianças. Na obra Brincar e se movimentar: tempos e espaços de vida da criança, organizada por Kunz (2015), os autores suscitam importantes reflexões acerca do modo impositivo com que as crianças têm sido tratadas em espaços destinados às atividades lúdicas e corporais na escola. Admitem a necessidade de se buscar um equilíbrio entre o espontaneísmo, em que toda a atividade corporal deve ser deixada a cargo das experiências e dos desejos da criança, e o direcionamento de toda e qualquer atividade, inclusive das brincadeiras. Em uma análise fenomenológica do movimento humano, o autor considera o movimento como o modo de comunicação com o mundo. Nesse entremeio, destaca-se a dimensão lúdica no tocante às especificidades da infância.

Portanto, os resultados da interpretação dos objetivos e conteúdos expressam uma disputa entre as diferentes abordagens pedagógicas da educação física. Contudo, cabe ressaltar que a realidade e a prática pedagógica se configuram de modo complexo e dinâmico. Por isso, alguns objetivos ou conteúdos, dependendo do plano de aula e da intencionalidade do professor, podem assumir diferentes enfoques e abordagens. Em adição, o Currículo de 2014, apesar de também incluir o caderno específico para a Educação Especial, elenca tópicos referentes a essa modalidade de ensino. Isso é evidenciado nos conteúdos da educação física, como "Jogos com regras adaptadas que possibilitem a participação de alunos com necessidades especiais" (Distrito Federal, 2014b, p. 60). A inclusão de pessoas com necessidades especiais é uma característica das teorias pós-críticas. Tal aspecto indica coerência entre pressupostos teóricos do currículo e objetivos e conteúdos do documento. 


\section{d) Infância no currículo}

Ao aproximar as temáticas currículo, educação física e infância, suscitamos reflexões, problematizando o lugar da infância no Currículo de 2014. Nesse contexto, alicerçadas nos pressupostos das teorias críticas e pós-críticas (Silva, 2002) da pedagogia histórico-cultural (Saviani, 2011) e da psicologia histórico-cultural (Vigotski, 1994), depreendemos que o sujeito que se pretende formar predominante no Currículo de 2014 é pautado em uma concepção crítica de infância (Oliveira, 2005). Mesmo considerando que alguns objetivos e conteúdos apresentados no documento remetam à concepção desenvolvimentista e à psicomotricidade, os pressupostos críticos se sobressaem. O trecho seguinte nos remete a essa criticidade, ao vislumbrar a formação de um sujeito autônomo e corresponsável.

Nessa etapa da vida, crianças de seis a dez anos são curiosas, questionadoras, sociáveis e dotadas de imaginação, movimento e desejo de aprender, sendo o lúdico bem peculiar dessa fase. Independentemente de sua condição de vida, buscam referências para formação de princípios a fim de enfrentar situações do cotidiano. Este é o momento em que a capacidade de simbolizar, perceber e compreender o mundo e suas diversidades, por meio de relações socioculturais, possibilita a estruturação de seu modo de pensar e agir no mundo, além da construção de sua autonomia e de sua identidade. Ao promover experiências pessoais e coletivas com o objetivo da formação de estudantes colaborativos, pesquisadores, críticos, corresponsáveis por suas aprendizagens, a escola ressignifica o currículo articulando conteúdos com eixos transversais e integradores (Distrito Federal, 2014b, p. 10, grifo nosso).

No que concerne ao Currículo de 2014, a dimensão lúdica é considerada um eixo integrador.

Considerando a importância da articulação de componentes curriculares de forma interdisciplinar e contextualizada, o currículo propõe ainda eixos integradores: alfabetização, somente para o Bloco Inicial de Alfabetização (BIA), letramentos e ludicidade para todo o Ensino Fundamental (Distrito Federal, 2014b, p. 9, grifo nosso).

Contudo, no estudo sobre a presença da dimensão lúdica em escolas públicas e privadas, Romera et al. (2007) observaram que, apesar de os professores terem a compreensão de que a ludicidade precisa estar presente cotidianamente na organização do trabalho pedagógico, há uma discrepância entre o discurso e a prática, sobretudo devido à quantidade de conteúdo que precisa ser desenvolvido em um tempo determinado. Registraram também situações nas quais os pais expressavam insatisfação quando as crianças brincavam na escola. Eles manifestavam preferir que fossem desenvolvidas atividades mais "produtivas" e não "perdessem tempo" brincando.

É importante ressaltar as contribuições da Sociologia da Infância para os professores de educação física que atuam com crianças. Para esse campo do conhecimento, os indivíduos “[...] se desenvolvem a partir da construção social das suas condições de existência e das representações e imagens historicamente construídas sobre e para eles” (Sarmento, 2005, p. 363). Conforme esse autor, a Sociologia da Infância supera a visão estritamente biológica ou psicológica para o desenvolvimento da criança, ao considerar a infância um objeto de pesquisa sociológico.

Cabe também destacar que a infância tem peculiaridades que precisam ser consideradas, como a brincadeira enquanto modo de a criança se expressar e de se relacionar com o mundo, a importância da dimensão lúdica nesse processo e a liberdade, necessária em alguns momentos, 
a despeito dos limites impostos pela organização dos tempos e espaços escolares. Ademais, um dos principais contributos da Sociologia da Infância para a educação e para educação física é considerar a criança um ser que precisa ser formado de maneira crítica e emancipatória, como sujeito que se expressa e, a partir da reprodução interpretativa (Corsaro, 2011), externaliza suas apropriações do mundo. Diante disso, a capacidade de se posicionar criticamente precisa ser estimulada desde a infância.

\section{e) Ciclos de aprendizagem}

Outro relevante e atual debate na SEDF é a organização dos tempos e espaços escolares em ciclos de aprendizagem. No Currículo de 2014, apesar de se considerarem as fases da criança, o aspecto mais importante é o tempo diferenciado para o aprendizado. O modo de organização curricular em ciclos intenta combater os altos índices de evasão e reprovação escolar por meio do rompimento da linearidade do trabalho pedagógico.

A principal oposição a esse modo de organização é a promoção automática dentro do mesmo ciclo, denominado por seus defensores como progressão continuada, ou seja, um tempo maior para aprender, não apenas em um ano letivo. Mas, para que haja êxito na implementação dos ciclos, sem que estes se reduzam ao aspecto da não reprovação, a implementação precisa ser gradativa, pois há uma considerável mudança no modo de planejamento e organização do trabalho pedagógico. Com isso os professores também precisam ser valorizados por meio de melhores condições de trabalho e formação continuada. São necessários, ainda, a participação da comunidade escolar e o apoio aos alunos com dificuldades de aprendizagem.

Quanto a esse aspecto, Souza Júnior (2007) analisou os fundamentos do currículo por ciclo de aprendizagem na rede municipal de ensino de Recife/PE e como se insere a educação física nesse contexto. $\mathrm{O}$ autor afirma que somente a mudança da nomenclatura não acarreta alterações estruturais, por isso outras medidas são necessárias. No caso da capital pernambucana, houve a implementação do Conselho de Ciclo, instância coletiva em que são discutidas, avaliadas e deliberadas ações a respeito da prática pedagógica, assim como os "Espaços Ampliados de Aprendizagens”, onde se desenvolvem atividades pedagógicas complementares em contraturno escolar.

Nessa perspectiva, a jornada ampliada de trabalho dos professores das escolas públicas de Brasília parece diferenciar o trabalho, se comparado o Distrito Federal a outros estados da Federação. Em geral, na capital federal, o professor leciona em um turno de cinco horas diárias, o que corresponde a 25 horas semanais, e no contraturno dispõe de 15 horas destinadas ao planejamento individual e coletivo na escola. Essa estrutura tende a favorecer a implementação do ciclo como forma de organização curricular, pois o professor, nos dias destinados ao planejamento, pode auxiliar os alunos que estão com dificuldades, de acordo com a necessidade e a demanda da escola.

O estudo de Fernandes (2012) sobre as repercussões da coordenação pedagógica na educação continuada e no trabalho docente de professores dos anos iniciais do Ensino Fundamental em uma escola pública de Brasília analisou avanços e tensões nesse importante momento pedagógico. As discussões entre professores que atuam em diferentes séries, além de possibilidade de planejamento e trabalho coletivo, foram apontadas como importantes avanços. Por outro lado, o estudo destacou, no âmbito da coordenação pedagógica, a falta de aprofundamento do nível teórico-prático e a descontinuidade dos estudos.

O planejamento do trabalho pedagógico de modo interdisciplinar é um tema recorrente na estruturação dos ciclos. Essas ações, porém, são insuficientes para que haja mudança de paradigmas, pois muitas resistências são enfrentadas por parte dos professores pelo modo linear e disciplinar a que estão acostumados ao lidar com as séries. Nessa conformidade, o PECM explicita a necessidade de um trabalho em parceria entre o professor de sala e o professor de 
educação física, detalhando questões teóricas e práticas da ação pedagógica na educação infantil e nos anos iniciais do Ensino Fundamental.

Essa perspectiva enfatiza a presença do professor de atividades como observador participante no processo ensino-aprendizagem conduzido pelo professor de Educação Física, visando à compreensão da especificidade da intervenção pedagógica desenvolvida por meio da cultura corporal. Reciprocamente, o professor de Educação Física buscará se aproximar do ambiente de aprendizagem e desenvolvimento propiciado pelos professores de atividades, criando condições para que ambos possam desenvolver o processo interdisciplinar no que se refere ao planejamento, execução e avaliação de suas intervenções pedagógicas (Distrito Federal, 2016, p. 7-8, grifo do autor).

O excerto anterior expressa o detalhamento de uma alternativa para o trabalho pedagógico interdisciplinar, partindo do planejamento em conjunto até a participação de ambos os professores no momento da aula em uma observação participante. Esse modo de organização é considerado importante, pois amplia a possibilidade de atuação dos professores de modo integrado, buscando romper com as dicotomias, conforme discutido por Sayão (1999; 2002), Ayoub (2001) e Buss-Simão (2010).

Em adição, o Coletivo de Autores (1992) é favorável à organização dos conteúdos da educação física em ciclos por propiciar uma visão de totalidade ao aluno e não tratar o conhecimento de modo isolado e fragmentado. Entretanto, muitas resistências são enfrentadas por parte dos professores, especialmente quanto à organização do trabalho pedagógico, pois ainda estão firmados no modo linear, etapista e disciplinar das séries.

\section{Conclusões}

O objetivo desta pesquisa foi analisar a proposta para a educação física nos anos iniciais do Ensino Fundamental nas escolas públicas de Brasília no Currículo de 2014, como forma de contribuir para o debate acerca das relações entre o currículo e a prática pedagógica da educação física escolar com crianças. Consideramos, nesse contexto, a relevância de uma formação inicial com qualidade, para que o professor se aproprie das discussões e produções existentes no campo acadêmico e se posicione criticamente, problematizando os elementos teóricos do currículo em diálogo com a prática pedagógica.

A partir das análises e inferências, concluímos que os pressupostos teóricos do Currículo de 2014 seguem uma linha fundamentada nas teorias críticas e pós-críticas de educação e educação física. Todavia, seus objetivos e conteúdos expressam disputas entre as diferentes abordagens da educação física, fundamentadas também em preceitos de teorias tradicionais.

Especificamente no campo da educação física, consideramos que as abordagens desenvolvimentista, construtivista-interacionista e psicomotora exprimem características de uma concepção predominantemente idealista de infância por sua ênfase em aspectos motores, cognitivos e psicológicos. No entanto, as abordagens crítico-superadora e crítico-emancipatória apontam a tendência de conceber a infância sob uma perspectiva sociocultural, e não apenas biológica.

Com base no que foi apresentado, observamos que o Currículo de 2014 compreende a educação física como um espaço para ampliação do repertório dos movimentos construídos culturalmente. Entretanto, ao investigar os objetivos e conteúdos, observamos a influência das demais abordagens, as quais enfatizam o gesto motor. O fato de a educação física na Educação Infantil e nos anos iniciais do Ensino Fundamental ser contemplada nos currículos também é relevante, mas o detalhamento por meio do PECM favorece e possibilita a permanência desse 
professor especialista na escola, enquanto não ocorre a sua almejada universalização nas escolas públicas de Brasília. A partir da inserção do professor de educação física atuando com crianças, identificamos na literatura pontos favoráveis quanto ao debate acerca da disciplina nesse nível de ensino, como a previsão do trabalho em parceria, sem hierarquizações, mas em uma relação de interdisciplinaridade e complementaridade.

Não pretendemos com isso menosprezar as importantes contribuições das formulações teóricas acerca das abordagens para a constituição do campo da educação física, menos ainda negar sua especificidade, que são as práticas corporais em suas diversas manifestações, como o esporte, a luta, a dança e os jogos. Entretanto, é razoável suscitar reflexões e debates que tratem o tema de maneira a permitir que as crianças aprendam a desempenhar papel de protagonismo na escola, com compreensão crítica de suas práticas corporais. Por fim, compreendemos que a universalização da educação física nas escolas públicas de Brasília é uma aspiração que depende preponderantemente de questões de ordem política e econômica, pois implica contratação de mais professores para compor o quadro docente da SEDF.

Indicamos a continuidade da pesquisa sobre a educação física na Educação Básica, pois após quatro anos foi lançada a segunda edição do Currículo em Movimento (Distrito Federal, 2018), para atender às demandas da BNCC e se adequar à universalização da organização escolar em ciclos para as aprendizagens.

\section{Notas}

1. Devido às peculiaridades do Distrito Federal, adotou-se o sistema de divisão territorial do Instituto Brasileiro de Geografia e Estatísticas (IBGE) utilizado pelos Correios, em que as Regiões Administrativas são consideradas bairros de Brasília e não cidades do Distrito Federal. Por isso, ao se referir às escolas de Brasília, são incluídas todas as escolas das cidades que compõem o Distrito Federal, e não apenas as da capital, localizadas no Plano Piloto.

2. Para uma escola pleitear a inserção no Projeto Educação com Movimento: Educação Física na Educação Infantil e nos anos iniciais, é necessário prever a ação em seu projeto político-pedagógico, manifestar interesse junto à Coordenação Regional de Ensino, além de apresentar espaço em que sejam possíveis as práticas corporais, como quadra e/ou área verde e/ou pátio, entre outros.

3. No Distrito Federal, a divisão territorial é feita por Regiões Administrativas, e não municípios, sendo 31 Regiões agrupadas em 14 Coordenações Regionais de Ensino.

4. Cabe ressaltar que a participação em cursos é facilitada, uma vez que os professores da SEDF, em regra, lecionam em apenas um turno. O contraturno é o tempo destinado ao planejamento em reuniões individuais, coordenações coletivas e formação continuada (Fernandes, 2012). Os cursos de formação continuada são oferecidos gratuitamente pela Subsecretaria de Formação Continuada dos Profissionais da Educação, conhecida como EAPE. Em geral, a coordenação ou reunião coletiva ocorre às quartas-feiras em todas as escolas da SEDF. Os professores e gestores têm a oportunidade de tratar de questões administrativas e pedagógicas, bem como de realizar estudos em grupo.

5. O termo Cultura Corporal de Movimento é utilizado por Kunz (1994), que trata da abordagem crítico-emancipatória. Contudo, consideramos que a ênfase nos excertos analisados está na abordagem crítico-superadora.

6. Apesar de não seguir o que determina a Associação Brasileira de Normas e Técnicas (ABNT), este é o modo como é conhecida esta obra clássica no campo da educação física.

\section{Referências}

ADAMSON, B.; MORRIS, P. Comparing Curricula. In: BRAY, M.; ADAMSON, B.; MASON, M. (Org.). Comparative Education Research: approaches and methods. Hong Kong, Hong Kong: Springer, 2007.

ANDRADE FILHO, N. Experiências de Movimento Corporal de Crianças no Cotidiano da Educação Infantil. São Paulo: Universidade de Campinas, 2011. 255f. Tese (Doutorado em Educação) - Universidade de Campinas, São Paulo, 2011.

APPLE, M. Ideologia e currículo. Porto Alegre: Artmed, 2008.

ARROYO, M. Currículo, território em disputa. 5. ed. Petrópolis: Vozes, 2013. 
AYOUB, E. Reflexões sobre a educação física na educação infantil. Revista Paulista da Educação Física, São Paulo, v. supl. 4, p. 53-60, 2001.

BARDIN, L. Análise de conteúdo. Lisboa: Edições 70, 2009.

BETTI, M.; FERRAZ, O.; DANTAS, L. Educação Física Escolar: estado da arte e direções futuras. Revista Brasileira de Educação Física e Esporte, São Paulo, v. 25, n. esp., p. 105-115, dez. 2011.

BOURDIEU, P. Os usos sociais da ciência: por uma sociologia clínica do campo científico. São Paulo: Editora UNESP, 2004.

BRASIL. Lei no 9.394 de 20 de dezembro de 1996. Estabelece as Diretrizes e Bases da Educação Nacional. Diário Oficial da União, Brasília, 23 dez. 1996.

BRASIL. Ministério da Educação. Secretaria de Educação Fundamental. Parâmetros Curriculares Nacionais, Brasília, 1997.

BRASIL. Lei n ${ }^{\circ} 11.274$, de 6 de fevereiro de 2006. Altera a redação dos arts. 29, 30, 32 e 87 da Lei no 9.394, de 20 de dezembro de 1996, que estabelece as diretrizes e bases da educação nacional, dispondo sobre a duração de 9 (nove) anos para o ensino fundamental. Diário Oficial da União, Brasília, 2006.

BRASIL. Resolução ${ }^{\circ} 7$ do Conselho Nacional de Educação. Diário Oficial da União, Brasília, 15 de dezembro de 2010, Seção 1, p. 34., 2010.

BRASIL. Diretrizes Curriculares Nacionais Gerais da Educação Básica. Ministério da Educação. Secretaria de Educação Básica. Diretoria de Currículos e Educação Integral. Brasília. 2013.

BRASIL. Base Nacional Comum Curricular. Ministério da Educação, Brasília, 2017. Disponível em: $<$ http://basenacionalcomum.mec.gov.br>. Acesso em: 30 nov. 2017.

BUSS-SIMÃO, M. Infância, corpo e educação na produção científica brasileira (1997-2003). 224 f. 2007. Dissertação (Mestrado em Educação) - Faculdade de Educação, Universidade Federal de Santa Catarina, Florianópolis: UFSC, 2007.

BUSS-SIMÃO, M. et al. Corpo e infância: natureza e cultura em confronto. Educação em Revista, Belo Horizonte, v. 26, n. 3, p. 151-168, dez. 2010.

COLETIVO DE AUTORES. Metodologia do ensino de Educação Física. São Paulo: Cortez, 1992.

CORSARO, W. Sociologia da Infância. Porto Alegre: Artmed, 2011.

CUNHA, É. V. R. D. Cultura, contexto e a impossibilidade de uma unidade essencial para o currículo. Currículo sem Fronteiras, São Paulo, v. 15, n. 3, p. 575-587, set./dez. 2015.

DEWEY, J. The child and the Curriculum. 7. ed. Illinois, USA: University of Chicago, 1963.

DISTRITO FEDERAL. Currículo em Movimento da Educação Básica: Pressupostos Teóricos do Currículo em Movimento da Educação Básica. Brasília: SEDF, 2014a.

DISTRITO FEDERAL. Currículo em Movimento da Educação Básica: Anos Iniciais do Ensino Fundamental. Brasília: SEDF, 2014b.

DISTRITO FEDERAL. Currículo em Movimento Ensino Fundamental: Anos Iniciais e Anos Finais. Brasília: SEDF, 2018a.

DISTRITO FEDERAL. Currículo em Movimento da Educação Básica. Secretaria de Estado de Educação, Brasília, 2019. Disponivel em: <http://www.educacao.df.gov.br/curriculo-emmovimento-da-educacao-basica-2/>. Acesso em 20 de agosto de 2019.

DISTRITO FEDERAL. Educação com Movimento: Projeto de inserção do professor de Educação Física na Educação Infantil e nos Anos Iniciais. Brasília: SEDF, 2016.

DISTRITO FEDERAL. Lei n ${ }^{\circ}$ 5.499, de 14 de julho de 2015. Aprova o Plano Distrital de Educação e dá outras providências. Diário Oficial do Distrito Federal, Brasília, 15 jul. 2015a.

DISTRITO FEDERAL. Secretaria de Estado de Planejamento, Orçamento e Gestão. Plano Plurianual 2016-2019, Brasília, 2015b. Disponivel em: <http://www.seplag.df.gov.br/planejamento-eorcamento/planejamento-governamental/299-ppa-2016-2019.html>. Acesso em 10 de jan. de 2018. 
FERNANDES, R. C. D. A. Educação continuada, trabalho docente coordenação pedagógica: avanços e tensões. In: VEIGA, I. P. A.; SILVA, E. F. D. A escola mudou. Que mude a formação de professores. São Paulo: Papirus, 2012. p. 83-114.

FERRAZ, O. L.; CORREIA, W. R. Teorias curriculares, perspectivas teóricas em educação física escolar e implicações para a formação docente. Revsita Brasileira de Educação Física e Esporte, São Paulo, v. 26, n. 3, p. 531-40, jul./set. 2012.

FREIRE, J. B. Educação de corpo inteiro: teoria e prática da Educação Física. São Paulo: Scipione, 1997.

GO TANI, E. A. Educação Física escolar: fundamentos de uma abordagem desenvolvimentista. São Paulo: EPU, 1988.

GOBBI, M. ; PINAZZA, M. (Org.). Infância e suas Linguagens. São Paulo: Cortez, 2014.

GOUVÊA, M. C. S. Infantia: entre a anterioridade e a alteridade. Educação \& Realidade, Porto Alegre, v. 36, n. 2, p. 547-567, maio/ago. 2011.

GRAMORELLI, L. C. A cultura corporal nas propostas curriculares da Educação Física: novas paisagens para um novo tempo. 2014. 188f. Tese (Doutorado em Educação) - Faculdade de Educação, Universidade de São Paulo. São Paulo: USP. 2014.

KIRK, D. Why research matters: Current status and future trends in physical education pedagogy. Movimento, Porto Alegre, v. 16, n. 2, p. 11-43, 11-43, abr.jun. 2010.

KUNZ, E. Transformação didático-pedagógica do esporte. Porto Alegre: UNIJUI, 1994.

KUNZ, E. Brincar e se movimentar: tempos e espaços de vida da criança. Porto Alegre: UNIJUI, 2015.

LACERDA, C. G. D.; COSTA, M. B. D. Educação Física na Educação Infantil e o Currículo da Formação Inicial. Revista Brasileira de Ciências do Esporte, Florianópolis, v. 34, n. 2, p. 327- 341, abr./jun. 2012.

LE BOULCH, J. Educação psicomotora: a psicocinética na idade escolar. Porto Alegre: Artmed, 2007.

MOREIRA, A. F. B. (Org.). Currículo: questões atuais. São Paulo: Papirus, 2010.

MOREIRA, P. S. S. Referenciais prescritos para educação infantil: diálogos com o professor de educação física. 2012. 176 f. Dissertação (Mestrado em Educação Física) - Universidade Federal do Espírito Santo, Centro de Educação Física e Desportos: UFES, 2012.

OLIVEIRA, N. R. C. D. Concepção de infância na educação física brasileira: primeiras aproximações. Revista brasileira de Ciências do Esporte, Curitiba, v. 26, n. 3, p. 95-109, maio 2005.

OLIVEIRA, S. S. D. Visualidades no componente curricular arte da rede pública de ensino do Distrito Federal: uma análise comparada dos currículos de 2000, 2009 e 2011 - ensino fundamental anos finais. 2014. 208f. Dissertação (Mestrado em Artes) - Universidade de Brasília, Brasília: UnB, 2014.

ROCHA, M. A. B. et al. As teorias curriculares nas produções acerca da Educação Física escolar: uma revisão sistemática. Currículo sem Fronteiras, São Paulo, v. 15, n. 1, p. 178-194, jan./abr. 2015.

ROMERA, L. et al. O lúdico no processo pedagógico da educação infantil: importante, porém ausente. Movimento, Porto Alegre, v. 13, p. 131-152, maio/ago. 2007.

SACRISTÁN, J. G. O que significa o currículo? In: SACRISTÁN, J. G. (Org.). Saberes e incertezas sobre o currículo. Porto Alegre: Penso, 2013. p. 16-35.

SAMPAIO, J. D. O. A Educação Física e a Perspectiva Histórico-Cultural: As apropriações de Vigotski pela produção acadêmica da área. 148f. Dissertação (Mestrado em Educação Física) Faculdade de Educação Física, Universidade de Brasília, Brasília. 2013: UnB, 2013.

SANCHOTENE, M. U.; MOLINA NETO, V. Habitus profissional, currículo oculto e cultura docente: perspectivas para a análise da prática pedagógica dos professores de educação física. Pensar a prática, Goiânia, v. 9, n. 2, p. 267-28, 2006.

SARMENTO, M. J. Gerações e alteridade: interrogações a partir da sociologia da infância. Educação e Sociedade, Campinas, v. 26, n. 91, p. 361-378, maio/ago. 2005. 
SAVIANI, D. Pedagogia histórico-crítica primeiras aproximações. Campinas: Autores associados, 2011.

SAYÃO, D. T. Educação Física na Educação infantil: Riscos conflitos e controvérsias. Motrivivência, Florianópolis, n. 13, p. 221-236, nov. 1999.

SAYÃO, D. T. Corpo e movimento: notas para problematizar algumas questões relacionadas à educação infantil e à educação física. Revista Brasileira de Ciências do Esporte, Campinas, v. 23, n. 2, p. 55-67, jan. 2002.

SILVA, T. T. D. Documentos de identidade: uma introdução às teorias do currículo. Belo Horizonte: Autêntica, 2002.

SOUZA JÚNIOR, M. Educação Física numa proposta pedagógica em ciclos de aprendizagens. Revista Brasileira de Ciências do Esporte, Campinas, v. 28, n. 2, p. 85-101, jan./mar. 2007.

VIGOTSKI, L. A formação social da mente. São Paulo: Livraria Martins Fonte, 1994.

\section{Correspondência}

Juliana de Oliveira Freire: É Professora de Educação Física da Secretaria de Educação do Distrito Federal e doutoranda em Educação na Universidade de Brasília.

E-mail: juliana2609@gmail.com

Ingrid Dittrich Wiggers: É Professora Doutora da Faculdade de Educação e de Educação Física da Universidade de Brasília.

E-mail: ingridwiggers@gmail.com

Aldecilene Cerqueira Barreto: É Professora de Educação Física da Secretaria de Educação do Distrito Federal e doutoranda em Educação Física na Universidade de Brasília.

E-mail: aldecilene@hotmail.com

Texto publicado em Currículo sem Fronteiras com autorização das autoras 